\title{
The Use of Mixed Oil Coating for Upgrading Borneo Brown Coal
}

\section{Herliati Rahman, Jaka Suryajaya Pratama, Rifka Kurnia Erviana}

Chemical Engineering Department, Jayabaya University, Jakarta, Indonesia

Email address:

herliatimulyono@gmail.com(H. Rahman)

\section{To cite this article:}

Herliati Rahman, Jaka Suryajaya Pratama, Rifka Kurnia Erviana. The Use of Mixed Oil Coating for Upgrading Borneo Brown Coal. Journal of Energy, Environmental \& Chemical Engineering. Vol. 4, No. 2, 2019, pp. 30-33. doi: 10.11648/j.jeece.20190402.12

Received: July 5, 2019; Accepted: August 7, 2019; Published: September 2, 2019

\begin{abstract}
Indonesia (Borneo) is an essential producer of coal in the world. Unfortunately, the resulting coal type is mostly in the low-rank, which called brown coal. This study was aimed to evaluate the influence of mixed oil coating to upgrade Borneo brown coal in terms of caloric value and water re-absorption. The additive material used to enhance brown coal is blended oil, such as used cooking oil and waste lubricant in various ratios. Coal samples were crushed and screening to obtain the required size 10 - 20 mesh ranges for analyses and experimentations. Each 50 g samples blended with the used cooking oil (UCO) and waste lubricant oil (WLO) at various ratios. Evaluation of thermal heat values and water re-absorption characteristics of original and coated coal have done. Compared to the first fuel, thermal heat values of coated coal were significantly improved. The result showed that coated coal has a resistance to water re-absorption. Also, the effect of mixed oil coating is highly significant to have high isothermal oxidation due to suppression of active functional groups to oxygen in the air. The study results also showed that increasing caloric value and lowering water content can be achieved significantly by this additive mixed oil.
\end{abstract}

Keywords: Brown Coal, Coating, Mixed Oil, Thermal Heat Value

\section{Introduction}

Indonesia (Kalimantan) is the five most abundant in the world as producers of coal. Unfortunately, the type of fuel is mostly in the low-rank, which is called brown coal [1]. Globally, low-rank coal constitutes more than $50 \%$ or more than $90 \%$ of Indonesia's Borneo Brown coal reserve (BCs) $[2,3]$. The price of low-rank coal is much lower compare to high-rank coal then BCs attracts attention around the world. However, because of their lower heating values $(5100-6100$ $\mathrm{kcal} / \mathrm{kg}$ ), and high moisture content $(25-60 \%)$ [4] of the utilization of BCs are limited [2]. High moistures content is a big problem because they influence on high transportation cost, fuel efficiency, and combustion energy products [5]. Government of Indonesia encourages some research to enhance the added value of both low and medium rank coal [2]. Afterward, improve the heating value and decreasing moisture content of low-rank fuel to increase the application of BCs become an interesting study. A characteristic of lowrank coal, they have a high tendency toward spontaneous combustion [6]. Upgrading of BCs is one promising way to meet these requirements.

Nowadays, Upgrading of BCs by dewatering technology is the favorite techniques [7]. This method has significantly improved the heating value and reduced the moisture content of brown coal. Therefore it can reduce the sensitivity of fuel toward spontaneous combustion [8]. Unfortunately, after drying, upgraded coal may have more pore than original, which make their moisture re-absorption more sensitive [9]. High moisture content not only relates to spontaneous combustion more potential but also the potential to make the heating value become lower $[6,10]$. Several studies have been done to investigate the effect of adding some fresh heavy oil on low-rank fuel. Unfortunately, in terms of operational costs, these methods are expensive because of raw material cost $[3,4]$; therefore, the use of alternative oil required.

During BCs storage, an exothermic reaction spontaneous combustion is highly potential occurred where oxidation of $\mathrm{BCs}$ at low temperatures $\left(<200^{\circ} \mathrm{C}\right)$ may occur. This problem is one of the most significant issues essential to discuss the safety issue [11]. The spontaneous combustion reaction 
causes serious environmental discussion, which emitted greenhouse gas such as carbon monoxide $(\mathrm{CO})$ and carbon dioxide $\left(\mathrm{CO}_{2}\right)$ [12]. To evaluated kinetics model of the reaction producing $\mathrm{CO}$ and $\mathrm{CO}_{2}$ from LTO of coal, and the factors influencing the emission of carbon gaseous in the exit gases both oxygen consumption and production rate were the main parameters measured for the evaluation of study [13, 14]. An alternative upgrading method strongly needed that can achieve the purpose mentioned above.

In this study, Indonesian BCs upgraded by adding used cooking oil, and waste lubricant in various ratios. It expected that said material would be useful to increase the heat value of upgraded BCs $[15,16]$. Besides, mixed materials are stored at room temperature in the liquid state and have ability to resistance on moisture [17]. Because of recycled oil, these materials very economist compared to fresh oil so the utilization of them for BCs up-gradation additive should be at a lower operational cost relatively. Furthermore, the present study focused on the observation impact of mixed recycled oil for BCs up-gradation on characteristics of the upgraded BCs. The thermal heat value of blended oil coating at $60.75 \mathrm{x}$ $103 \mathrm{~kJ} / \mathrm{kg}$, so it expected could effectively improve the heating value of upgraded BCs.

\section{Materials and Method}

Samples of Indonesian (Borneo) brown coal used as raw coal. The raw coal cleaned from impurity to obtain good coating, then they were stored at room temperature with sufficient lighting. Representative samples were crushed and screening to get the required size 10-20 mesh ranges for analyses and experimentations. Each $50 \mathrm{~g}$ sample mixed with the used cooking oil (UCO) and waste lubricant oil (WLO) at various ratios. The waste lubricant oils were obtained and collected from an oil service station while UCO can found in vast quantities such as restaurants, food courts, and cafeterias. UCO and WLO were the additive agents used to stabilize the BCs.

Heating value and proximate analysis conducted using Bomb Calorimeter Parr 6200 ASTM D 5865-10a method and ASTM D3172-07a using TGA701 thermogravimetric analyzer, respectively. The properties of BCs and additive gave in Table 1. The surface areas of the coal samples were examined using the Brunauer-Emmett-Teller (BET) method [18]. Before BET surface area analysis, the samples were heated to $110^{\circ} \mathrm{C}$ for $12 \mathrm{~h}$ in an $\mathrm{N} 2$ environment. BET analysis starts by cooling down the sample to $\sim 77 \mathrm{~K}$, followed by nitrogen injection under various pressure to determine N2 displacement for specific are a calculation. [19]

\section{Results and Discussion}

\subsection{Characteristic of Raw and Upgraded Coal}

Proximate analysis and thermal heat values of raw and upgraded coal shown in Table 1. The moisture content of upgraded coal decreased up to $15-30 \%(w / w)$. Originally fresh coal had $17.75 \%(\mathrm{w} / \mathrm{w})$ moisture content. Not only decreasing the moisture content of upgraded coal at the same time, but mixed oil can also increase thermal heat values significantly. In the case of thermal heat value raw coal, which initially has $4868 \mathrm{kcal} / \mathrm{kg}$ increase up to $6412 \mathrm{kcal} / \mathrm{kg}$ maximum with ratio waste lubricant: used cooking oil at 1: 2 .

Table 1. Raw and treated coal proximate analysis and heating values.

\begin{tabular}{|c|c|c|c|c|c|}
\hline Samples & Moisture\% & HV Kcal/kg & Volatile\% & Ash \% & FC\% \\
\hline BCs (as received) & 17.75 & 4868 & 36.34 & 5.53 & 29.77 \\
\hline $\mathrm{UCO}$ & 3.62 & 7283 & - & - & - \\
\hline WLO & 5.96 & 6166 & - & - & - \\
\hline $1: 0.25$ & 4.2 & 5443 & & - & - \\
\hline $1: 0.75$ & 3.9 & 5627 & & - & - \\
\hline $1: 1.5$ & 3.61 & 6234 & & - & - \\
\hline $1: 2$ & 3.74 & 6412 & & - & - \\
\hline $1: 3$ & 4.1 & 6356 & & - & - \\
\hline $1: 4$ & 4.75 & 6243 & & - & - \\
\hline
\end{tabular}

To evaluate the effect of coating on treated coal for surface area and pore volume, some testing, using BET, was done as Table 2 shows. The BET's testing result shows that surface area in raw coal was $2.41 \mathrm{~m}^{2} / \mathrm{g}$ and after coating it reduced sharply up to $0.97 \mathrm{~m}^{2} / \mathrm{g}$. This phenomena potentially occurred because the upgrading additive fulfills the pores and replace the hydrate water during the process of upgrading. Also, the same trend, as compared to raw coal, in pore volumes after coating, particles experience coating and clogging with each other.

Table 2. Original and treated coal surface area and pore volume.

\begin{tabular}{lll}
\hline Samples & Surface Area, BET $\left(\mathbf{m}^{2} / \mathbf{g}\right)$ & Pore Volume $\left(\mathbf{c m}^{3} / \mathbf{g}\right)$ \\
\hline BCs (as received) & 2.41 & 0.0172 \\
BCs-mixed oil $10 \%(\mathrm{v} / \mathrm{v})$ & & \\
WLO: UCO 1:2 & 0.97 & 0.0079 \\
\hline
\end{tabular}


Figure 1(a) shows a macroscopic image of raw coal before coating, and Figure 1(b) shows the upgraded coal, respectively. The shinning parts of the pictures indicate the additive oils coating occupy the pore of particles coal surface after drying step. On the other hand, the oils coating UCO and WLO were spread on the coal surface very well. It means the upgraded coal should well protect from the moisture re-absorption and oxidation.

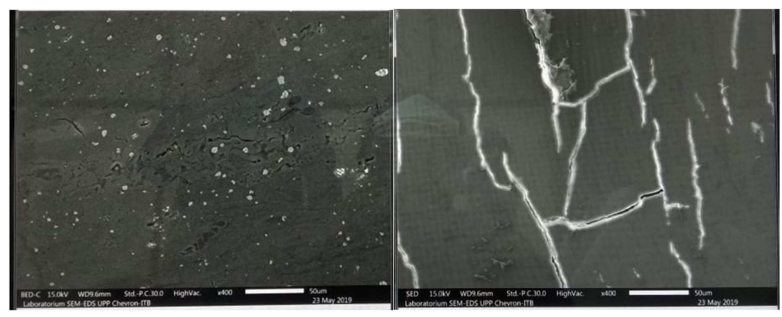

(a)

(b)

Figure 1. (a) Macroscopic image of the raw coal (b) treated coal particles (10-20 mesh).

\subsection{Upgraded-Coal Coating Process}

BCs was feed into a secondary mill to have smaller particle and sorted by a screen to have a particle size in range 10 - 20 mesh. All samples similar around $10 \%$ pulverized coal was put in the oven at $110^{\circ} \mathrm{C}$ for $70 \mathrm{~min}$. Drying also provides more pore so that mixed oil can coat the upgraded coal. Each $50 \mathrm{~g}$ sample mixed with oil coating which heated until $200^{\circ} \mathrm{C}$ and continuously stirred at constant speed 100 rpm to intimate contact the surface coating of coal particles. The upgrading coal separates from oil coating using a vacuum filter. A brief step process of the upgraded coal manufacturing process was described in Kinoshita et al. [20]

\subsection{Characteristics Water re-absorption}

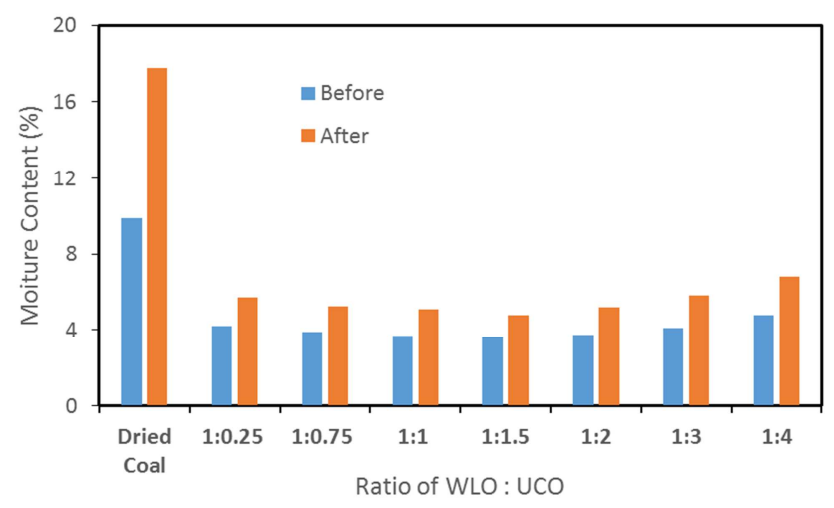

Figure 2. Water re-absorption characteristics original and treated coal.

Water re-absorption characteristics of BCs before and after coating are examined by equilibrium moisture method. Standard Test Method for Equilibrium Moisture of Coal at 97 Percent Relative Humidity and $30^{\circ} \mathrm{C}$, ASTM D-1412-02a, was used [4]. This goal conducted was $50 \mathrm{~g}$ coal put into the glassware. It was stirred in a water bath for 12 hours and then stored in a humidity chamber for 72 hours at $97 \%$ relative humidity and $30^{\circ} \mathrm{C}$ as standard procedure explained by Khan et al. $[5,21]$. Furthermore, the moisture content of dried and upgraded coal determined by proximate analysis. The results of the experiments showed in Figure 2.

\subsection{Evaluation of the Degree of Spontaneous Combustion}

A spontaneous combustion reaction is one of the critical problems of coal. All coal oxidizes when they start to expose to air, especially during and after mining [22]. This thing tends to be more of a problem in lower rank coal like lignite. One of the parameters used to assessing coal characteristic is crossing point temperature (CPT) or relative ignition temperature $[5,22]$. It is the temperature at which the coal temperature begins to exceed the surrounding temperature. It is reported that coal with a CPT of $120-140^{\circ} \mathrm{C}$ and a moisture content of more than $5 \%$ is highly susceptible to spontaneous combustion [22]. To evaluate the selfcombustion characteristics of raw and upgraded coal, CPT assessed. For this purpose, the $50 \mathrm{~g}$ coal samples heated in a reaction tube of the furnace for 2 hours at rising temperature. Nitrogen passing through it at $80 \mathrm{ml} / \mathrm{min}$ rate until the coal temperature crosses the furnace temperature. The point where the heat of the furnace started to increase compared to the coal temperature considered as the CPT. Figure 3 shows that CPT of treated coal was improved significantly. A detailed description of the CPT measuring apparatus described in many kinds of literature.

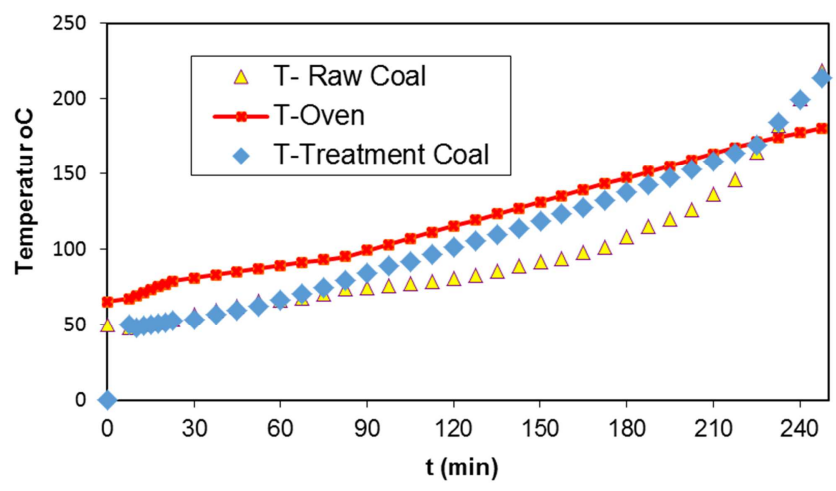

Figure 3. CPT measurements.

\section{Conclusion}

In this report, low-rank coal, from Kalimantan (Borneo) Indonesia upgraded by the addition of waste lubricant oil and used cooking oil in various ratio. Characteristics of upgraded coal such as thermal heat values, spontaneous combustion, water re-absorption, and isothermal oxidation evaluated. This study shows that in ratio waste lubricant to used cooking oil at 1: 2 has the most substantial potential to improve BCs, not only for higher heat calorific values but also for lower water re-absorption, and finally for a medium tendency to spontaneous combustion. 


\section{Acknowledgements}

Many thanks for funding supported by Jayabaya University through the research grant with a contract number: $71.02 / \mathrm{DEK} / \mathrm{FTI}-\mathrm{UJ} / \mathrm{XII} / 2018$ so this research can be accomplished completely.

\section{References}

[1] Heri Heriyanto, W. Ernayati, M. Yulvianti and Sutijan, "The Influence of Kerosene to Increase the Quality of Coal from Bayah South Banten Using UBC Methode," World Chemical Engineering Journal, vol. 1, no. 1, pp. 6-10, 2015.

[2] G. Gushka, "The Low Rank Coal Policies In Indonesia," Directorate General Of Mineral And Coal, Tokyo, 2013.

[3] M. Z. Khan, D. H. Chun, a. S. D. K. Jiho Yoo, a. H. K. C. J. L. Young Joon Rhim, S. Lee and A. Rifellaa, "Evaluation of the effect of a palm acid oil coating on upgrading low rank coal, " Royal Society of Chemistry Advanced, vol. 5, no. 1, p. 6395563963, 2015.

[4] M. Z. Khan, D. H. Chun, Y. J. Rhim, S. D. Kim, J. Yoo, H. Choi, J. H. Lim, W. T. Jo and S. Lee, "Upgrading Indonesian Low-Rank Coal with an Oil Coating," International Journal of Coal Preparation and Utilization, p. 251-261, 2016.

[5] M. Z. Khan and D. H. Chun, "Upgrading Indonesian LowRank Coal with an Oil Coating," International Journal of Coal Preparation and Utilization, vol. 36, no. 5, p. 251-261, 2015.

[6] C. E. J. Center, K. Steel and Ltd, "UBC (Upgraded Brown Coal) Process Development," Kobe Steel Engineering Reports, pp. 77-78, 2003.

[7] Y. Huang, Y. Wang, H. Zhou, Y. Gao, D. Xu and L. Bai, "Effects of Water Content and Particle Size on Yield and Reactivity of Lignite Chars Derived from Pyrolysis and Gasification," Molecules, vol. 23, no. 10, p. 2717, 2018.

[8] A. A. Vostrikov, D. Y. Dubov, M. Y. Sokol, A. V. Shishkin and O. N. Fedyaeva, "Brown coal gasification in combustion in supercritical water," Journal of Engineering Thermophysics, vol. 25 , no. 1 , pp. 55-66, 2016.

[9] O. J and J. Willey and Sons, "Adsorption," Ellis Herwood Series in Physical Chemistry, 1994.

[10] "Study on Clean Coal Technology Project," The Institute of Energy Economics, Japan, Tokyo, 2012.

[11] J. D. N. Pone, K. A. Hein, G. B. Stracher, H. J. Annegarn, R. B. Finkleman, D. R. Blake, J. K. McCormack and Paul, "The spontaneous combustion of coal and its by-products in the Witbank and Sasolburg," Coal Geology, 2007.

[12] Indocement, "Proses UBC Batubara dengan bantuan minyak pelumas atau oli bekas," 2014.
[13] J. A. DeBarrl, M. Rostam-Abadi and S. A. Benson', "Combustion Properties of Illinois Coal-Char Blends," Energy \& Environmental Research, 2000.

[14] L. Yuan and A. C. Smith, "CO and $\mathrm{CO}_{2}$ emissions from spontaneous heating of coal under different ventilation rates," Office of Mine Safety and Health Research, United State, 2011.

[15] O. L. E. and D. S. M. L. C. P, "Comparative study of calorific value of rapeseed, soybean, jatropha curcas and crambe biodiesel," in International Conference on Renewable Energies and Power Quality (ICREPQ'13), Spain, 2013.

[16] D. V. R. Mamilla and D. L. N. R. G, "A review: Waste lubricating oil as an alternative fuel blended with diesel," International Journal of Advanced Scientific Research, vol. 1, no. 1, pp. 1-4, 2016.

[17] R. Permadi, L. Pulungan and Solihin, "Analisis Batubara Dalam Penentuan KualitasBatubara Untuk Pembakaran Bahan BAku Semen di PT. Indocemet Tunggal Prakarsa Tbk. Palimanan-Cirebon," Unisba, Bandung, 2015.

[18] G. N. Okolo, R. C. Everson, H. W. Neomagus, M. J. Roberts and R. Sakurovs, "Comparing the porosity and surface areas of coal as measured by gas adsorption, mercury intrusion and SAXS techniques," Fuel, vol. 141, pp. 293-304, 2015.

[19] D. r. n. B. Hellack, SOP: Specific Surface Area Analysis by BET Theory, 2016.

[20] S. Kinoshita, D. S. Yamamoto, T. Deguchi and T. Shigehisa, "Demonstration of Upgraded Brown Coal Process by 600 Tonnes/day Plant," P. T Upgraded Brown Coal Indonesia, Tokyo, 2010.

[21] S. Murata, K. Kidena, M. Hosokawa and M. Nomura, "Analysis of oxygen-functional groups in brown coals," Fuel Processing Technology, pp. 231-243, 2000.

[22] D. L. L. Sloss, "Assessing and managing spontaneous combustion of Coal," IEA Clean Coal Centre, London, 2015.

[23] H. Choi, C. s. Thiruppathiraja, S. Kim, Y. Rhim, J. Lim and S. Lee, "Moisture readsorption and low temperature oxidation characteristics of upgraded low rank coal, " Fuel Processing Technology, vol. 92, no. 10, pp. 2005-2010, 2011.

[24] K. Akiyama, H. Pak, Y. Ueki, R. Y. and I. Naruse, "Effect of $\mathrm{Mg}$ based addition to Upgraded Brown Coal on the Ash Deposition Behavior During Combustion," MCS 7, pp. 11-15, 2011.

[25] T. Sugita, "Low-rank Coal Upgrading Technology (UBC Process)," Kobe Steel Engineering Reports, Tokyo, 2003.

[26] G. Wang, J. Xie, S. Xue and H. Wang, "Laboratory Study On Low-Temperature Coal Spontaneous Combustion in The Air Reduced Oxygen and Low Methane Consentration," Technical Gazette, vol. 22, no. 5, pp. 1319-1325, 2015.

[27] A. J. Al-Kofahi, "Waste Cooking Oil to Biodiesel Fuel," American University of Beirut, America, 2017. 